\title{
CAPÍTULO 05: AVALIAÇÃO DA CAPACIDADE ANTIOXIDANTE E ANTIMICROBIANA DE EXTRATOS DE FOLHAS DE MORINGA
}

\section{CHAPTER 05: EVALUATION OF ANTIOXIDANT AND ANTIMICROBIAL CAPACITY OF MORINGA LEAF EXTRACTS}

\author{
Marina Silva ${ }^{1}$; Mabel Câmara Araújo²; Luciano Tormen ${ }^{3}$; Cátia Tavares dos Passos Francisco ${ }^{4}$; Eduarda Molardi \\ Bainy $^{5}$
}

\begin{abstract}
Resumo
Moringa oleifera é uma planta originária da Índia conhecida por propriedades funcionais e medicinais. A utilização de solventes variados para obtenção de extratos, por extrair compostos distintos, pode resultar em comportamentos antioxidante e antimicrobiano diferentes. $\mathrm{O}$ objetivo do presente estudo foi avaliar capacidade antioxidante e antimicrobiana de extratos de folhas de $M$. oleifera, obtidos por decocção em água, extração hidroalcóolica e em extrator Soxhlet com etanol. Os extratos foram avaliados quanto ao teor de compostos fenólicos pelo método de Folin-Ciocalteau, capacidade de sequestro do radical DPPH e pela capacidade de redução do íon férrico, bem como, atividade antimicrobiana por difusão em ágar testando bactérias Gram-positivas e Gram-negativas. Os rendimentos em massa dos extratos variaram entre 14,0 para extração hidroalcóolica a 43,9\% para decocção. A concentração de compostos fenólicos resultou de 26,6 a $36,5 \mathrm{mg}^{\mathrm{A} G} \mathrm{~g}^{-1}$. A capacidade de sequestro do radical DPPH variou de 29,9 a 64,9 mg Trolox $\mathrm{g}^{-1}$. Com relação a capacidade de redução do íon férrico, foram obtidos resultados entre 67,7 e 138,5 $\mathrm{mg}^{\text {Trolox g}}{ }^{-1}$. Os extratos não apresentaram ação antimicrobiana. A extração por decocção apresentou melhor rendimento e capacidade antioxidante. Assim, a capacidade antioxidante dos extratos está diretamente ligada às condições de extrações submetidas.
\end{abstract}

Palavras-Chaves: Moringa, folhas, extração, compostos fenólicos totais, antioxidante.

\begin{abstract}
Moringa oleifera is a plant originally from India, known for its functional and medicinal properties. The application of different solvents to obtain extracts can cause different antioxidant and antimicrobial effects due to the ability to extract different compounds. The objective of the present study was to evaluate the antioxidant and antimicrobial capacity of $M$. oleifera leaf extracts, obtained by water decoction, hydroalcoholic extraction and Soxhlet extractor with ethanol. The extracts were calculated according to the content of total phenolic compounds by the Folin-Ciocalteau method, the DPPH sequestration capacity and ferric ion reducing capacity, and antimicrobial activity by diffusion in agar, testing Gram-positive and Gram-negative bacteriae. The weight yield of the extracts varied between 14.0 for hydroalcoholic extraction to $43.9 \%$ for decoction. The concentration of total phenolic compounds resulted in 26.6 to $36.5 \mathrm{mg}$ of $\mathrm{AG} \mathrm{g}^{-1}$. The DPPH sequestration capacity ranged from 29.9 to $64.9 \mathrm{mg}$ of Trolox $\mathrm{g}^{-1}$. Regarding the ferric reducing capacity, results were between 67.7 and $138.5 \mathrm{mg}$ of Trolox $\mathrm{g}^{-1}$. The extracts did not have antimicrobial action. Decoction extraction had better yield and antioxidant capacity. Thus, the antioxidant capacity of the extracts is directly linked to the extraction conditions.

\footnotetext{
${ }^{1}$ Engenharia de Alimentos, Universidade Federal da Fronteira Sul, marina15.06@ hotmail.com

${ }^{2}$ Engenharia de Alimentos, Universidade Federal da Fronteira Sul, mabel.caraujo@ gmail.com

${ }^{3}$ Engenharia de Alimentos, Universidade Federal da Fronteira Sul, luciano.tormen@uffs.edu.br

${ }^{4}$ Engenharia de Alimentos, Universidade Federal da Fronteira Sul, catia.passos@uffs.edu.br

${ }^{5}$ Doutora, Universidade Federal da Fronteira Sul, eduarda.bainy@uffs.edu.br
} 
Keywords: Moringa, leaves, extraction, total phenolic compounds, antioxidant.

\section{Introdução}

Moringa oleifera é a planta representante da família Moringaceae, originária da Índia com 14 espécies nativas, distribuída em países de clima tropical e introduzida no Brasil na década de 60 (BARRETO et al., 2009; MORTON, 1991). Suas folhas, flores, vagens, raízes e sementes são utilizadas para diversos fins, como coagulante natural para purificação da água (KALOGO et al., 2000), obtenção de biodiesel (RASHID et al., 2008), obtenção de extratos (RODRÍGUEZ et al., 2016; ZHAO et al., 2013), na medicina tradicional (ANWAR et al., 2007) e devido a presença de fitoquímicos e sua composição nutricional (AMAGLO et al., 2010; SAINI et al., 2016) tem enriquecido formulações alimentares (OYEYINKA et al., 20196 SAUCEDO et al., 2018).

As diferentes partes de $M$. oleifera apresentam rica composição de compostos bioativos (BARRETO et al., 2009; STOHS et al., 2015), sendo as folhas responsáveis por níveis consideráveis de compostos fenólicos, ácido ascórbicos, flavonoides, carotenoides, aminoácidos, esteróis e óleos essenciais (BARRETO et al., 2009; MOYO et al., 2011; NOUMAN et al., 2016; ÖZCAN, 2020). No entanto, a presença desses compostos pode variar dependendo do estágio de maturação da M. oleifera (SREELATHA et al., 2009), tipos de cultivares (NOUMAN et al., 2016), assim como métodos e condições de extrações (HAMANY et al., 2018; RODRÍGUEZ et al., 2015).

Durante o processo de obtenção dos extratos, há fatores que influenciam o extrato final, como tipo de solvente, método de extração utilizado, tempo, temperatura e pressão (AZMIR et al., 2013), o que pode levar a variações no rendimento e na composição (CELEP et al., 2019; DE SOUZA et al., 2018). A escolha de qual solvente orgânico utilizar durante o processo para obtenção de extratos a partir de matérias primas vegetais, devido a polaridade e a afinidade entre o solvente a matriz vegetal, é um dos principais fatores que influenciam na eficiência da extração (AZMIR et al., 2013), sendo necessário considerar também o custo, transferência de massa, toxidade e disponibilidade para execução.

Métodos convencionais de extração, como o uso de equipamento Soxhlet com solventes orgânicos, são classificados em desvantagens, uma vez que podem causar danos ao meio ambiente, utilizam grande volume de solvente, alto custo, longo tempo de extração, baixa seletividade (HERRERO et al., 2015; OUÉDRAOGO et al., 2018), e também por degradarem compostos termolábeis de interesse presentes na matriz vegetal (DE SOUZA et al., 2018; GARCIA et al, 2010). Por outro lado, extrações utilizando condições sustentáveis são 
consideradas benéficas (BOEING et al., 2014; CELEP et al., 2019; ROCCHETTI et al., 2020), uma vez que apresentam capacidade de extrair ampla gama de compostos bioativos, extratos seguros para aplicações alimentares e farmacêuticas, baixo custo e não causam danos ao meio ambiente (AZMIR et al., 2013; MARTINS et al., 2015).

Autores anteriores com estudos de folhas de M. oleifera, relataram diferentes formas para obtenção de extratos, como métodos de extração por infusão hidrometanólica $70 \%$ (NOUMAN et al., 2016), maceração, decocção, extração assistida por ultrassom e microondas com o uso de água (CASTRO et al., 2017) e maceração e extração assistida por ultrassom com o uso de metanol, etanol e acetona como solvente (RODRÍGUEZ et al., 2015). Os trabalhos de Zhao et al. (2013) e Rodríguez et al. (2016) avaliaram as condições de extração de folhas de $M$. oleifera, composição dos extratos, a presença de compostos fenólicos totais, atividade antioxidante, e, relataram que há variações na composição final e quantidade de compostos bioativos presentes nos extratos, dependendo do método e do solvente de extração utilizado. Outro estudo sobre extração de compostos fitoquímicos de partes aéreas de M. oleifera por tecnologias não convencionais, Hamany et al. (2018) relataram que extrações utilizando solventes sustentáveis e condições de pressão e temperatura, são eficientes para extrair ampla gama de compostos, sendo estes, responsáveis pelas características bioativa da planta (ANWAR et al., 2007; FAROOQ et al., 2020; HAMANY et al., 2018; SAUCEDO et al., 2018).

Desta forma, o objetivo principal do presente estudo foi obter extratos de folhas de $M$. oleifera utilizando extração convencional por Soxhlet com etanol, extração hidroalcóolica e por decocção com água. Os extratos obtidos foram avaliados quanto ao rendimento em peso, quantificação de compostos fenólicos totais (CFT), capacidade de sequestro do radical 2,2difenil-1-picrilhidrazil (DPPH), redução de íon férrico 2,4,6-tri(2-piridil)-s-triazina (TPTZ) e, atividade antimicrobiana para bactérias Gram-positivas e Gram-negativas.

\section{Material e Métodos}

\section{Material vegetal}

As partes aéreas da Moringa oleifera foram obtidas na região oeste do Paraná, Brasil, por doação. As folhas (Figura 1) foram lavadas com água corrente, sanitizadas com solução de hipoclorito (100 ppm) e secas em estufa com circulação de ar forçado a 323,15 K até massa constante. Após as folhas foram trituradas em processador de alimentos doméstico durante 30 minutos, seladas à vácuo e armazenadas até sua utilização configurando um lote único. 


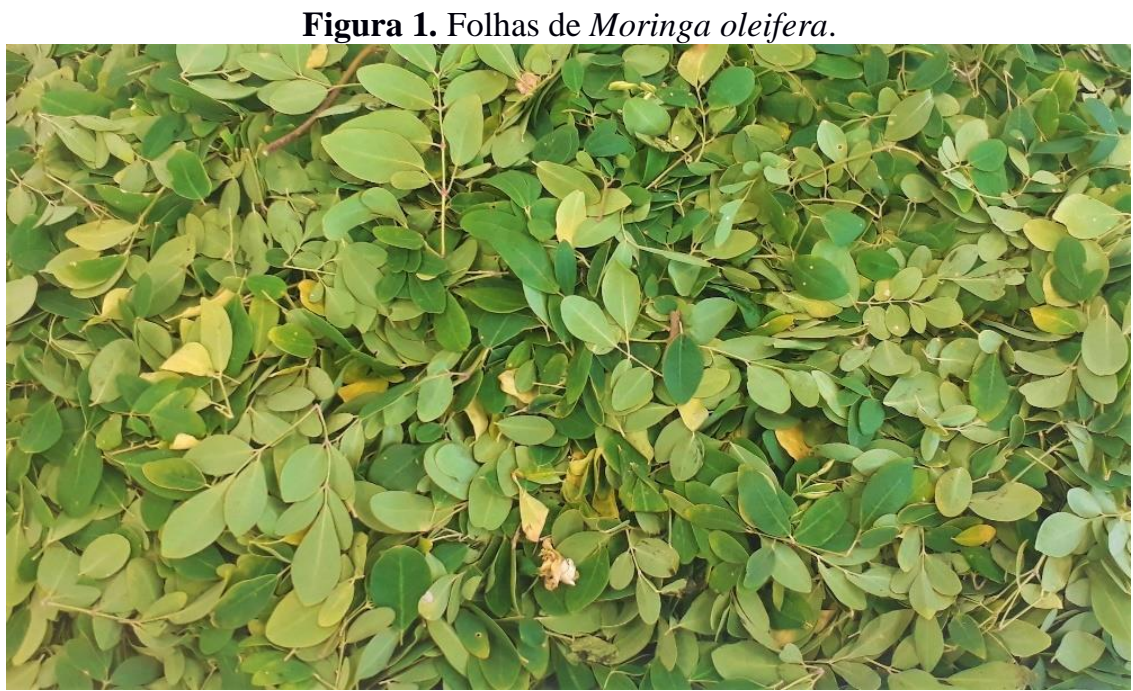

Fonte: Própria (2020).

\section{Extração em Soxhlet}

A extração em extrator Soxhlet utilizou o solvente orgânico etanol 99\%. O processo de extração foi conduzido segundo o método oficial da AOAC 1999 com modificações. A extração ocorreu com a massa de $5 \mathrm{~g}$ de amostra para $150 \mathrm{~mL}$ de solvente em ebulição por 6 horas. No final, o solvente foi removido utilizando evaporador rotativo sob pressão reduzida (Quimis, São Paulo, Brasil) a 333,15 K até massa constante. O extrato foi armazenado na ausência de luz até seu uso.

\section{Extração por decocção}

A extração por decocção utilizou água como solvente e foi conduzida de acordo como descrito anteriormente por Martins et al. (2015) com modificações. Em um sistema de bancada foi utilizando água destilada na proporção de 10:1 (água:amostra) em massa. A mistura foi mantida sob temperatura de ebulição por 5 minutos e deixada em repouso por mais 5 minutos antes de ser filtrada sob pressão reduzida. A água foi removida por evaporador rotativo sob pressão reduzida a 333,15 K até massa constante e o extrato armazenado na ausência de luz até seu uso.

\section{Extração hidroalcóolica}

A extração hidroalcóolica foi conduzida segundo metodologia descrita anteriormente (DE OLIVEIRA et al., 2015) com modificações. A mistura etanol/água na proporção 70:30 em volume, sob temperatura ambiente em bancada utilizando a proporção de 10:1 (solvente:amostra) em massa, foi mantida sob homogeneização por $1 \mathrm{~h}$ e em seguida filtrada por pressão reduzida. Sobre o resíduo resultante foi realizado o processo de extração descrito por mais duas vezes. $\mathrm{O}$ solvente dos extratos combinados foi removido por evaporador rotativo sob pressão reduzida a 333,15 K até massa constante, e armazenado na ausência de luz até seu 
uso.

\section{Compostos fenólicos totais}

A quantificação de compostos fenólicos totais foi determinada pelo método de FolinCiocalteau descrita por Minussi et al. (2003) com modificações e realizada em triplicata. A dissolução dos extratos ocorreu com $10 \mathrm{mg}$ de amostra em $10 \mathrm{~mL}$ de etanol 99\%, homogeneizados em agitador magnéticos com ausência de luz. Após a dissolução em tubo cônico foram adicionados 0,2 mL de extrato, 2,0 mL do reagente Folin-Ciocalteu 10\% (v/v), 1,0 $\mathrm{mL}$ de carbonato de sódio 7,5\% (m/v) e $6,8 \mathrm{~mL}$ de água destilada. A mistura foi homogeneizada com ausência de luz e mantida em repouso por 2 horas. A determinação de absorbância foi realizada em espectrofotômetro UV-visível (Evolution 201, Thermo Scientific) no comprimento de onda de $765 \mathrm{~nm}$. A curva padrão foi realizada utilizando ácido gálico. Os resultados foram expressos em miligrama equivalente de ácido gálico por grama de extrato (mg $\left.\hat{A} G g^{-1}\right)$.

\section{Eliminação do radical DPPH}

A atividade antioxidante por método de eliminação, foi determinada pela capacidade de sequestro do radical 2,2-difenil-1-picrilhidrazil (DPPH) presente nos extratos. A determinação foi realizada em triplicata, segundo a metodologia de Rufino et al. (2007) com modificações. A dissolução dos extratos ocorreu a partir de $20 \mathrm{mg}$ de amostra e $5 \mathrm{~mL}$ de acetona 99,5\%. A solução de DPPH foi preparada na concentração de $60 \mu \mathrm{M}$. Para determinar a absorbância foi utilizado espectrofotômetro UV-visível (Evolution 201, Thermo Scientific) e realizada a leitura em $515 \mathrm{~nm}$. A curva padrão foi realizada utilizando o reagente $( \pm)$-6-hidroxi-2,5,7,8tetrametilcromano-2-carboxílico(Trolox), e os resultados expressos em miligrama equivalente de Trolox por grama de extrato ( $\mathrm{mg}$ Trolox $\mathrm{g}^{-1}$ ).

\section{Redução do íon férrico}

A atividade antioxidante também foi determinada através da capacidade de redução do íon férrico 2,4,6-tri(2-piridil)-s-triazina (TPTZ), descrito por Rufino et al. (2006) com modificações. A dissolução do extrato ocorreu com $20 \mathrm{mg}$ de amostra e $10 \mathrm{~mL}$ de acetona 99,5\%. Alíquotas de $100 \mu \mathrm{L}$ de extrato foram transferidas para tubo cônico com $0,2 \mathrm{~mL}$ de água destilada, 2,7 mL de solução FRAP e incubadas a 308,15 K por 30 min. A curva padrão foi preparada com Trolox, e a leitura da absorbância determinada em espectrofotômetro UV-visível (Evolution 201, Thermo Scientific) no comprimento de onda de $595 \mathrm{~nm}$. O potencial antioxidante foi expresso em miligrama equivalente de Trolox por grama de extrato (mg Trolox $\left.\mathrm{g}^{-1}\right)$. 


\section{Atividade antimicrobiana}

As atividades antimicrobianas dos extratos de folhas de $M$. oleifera foram realizadas pelo método de difusão em ágar segundo a metodologia de Czaikoski et al. (2015). Foram testadas três bactérias Gram-negativas: Salmonella typhimurium, Escherichia coli e Pseudomonas aeruginosa; e duas Gram-positivas: Staphylococcus aureus e Listeria monocytogenes. O resultado foi expresso pela medição do diâmetro do halo.

\section{Análise estatística}

Os resultados foram avaliados por análise de variância (ANOVA), no qual determina a diferença com 95 \% de significância. O Teste de Tukey foi utilizado para comparar médias (p $<0,05)$ quando houve diferença significativa entre compostos fenólicos totais e a atividade antioxidante pelo método de sequestro do radical DPPH e redução de íon férrico (FRAP).

\section{Resultados e Discussão}

\section{Rendimento}

A Tabela 1 apresenta os resultados de rendimento dos extratos de folhas de $M$. oleifera obtidos pelos três métodos de extrações aplicados. O método por decocção em água apresentou maior rendimento $(44,0 \%)$, seguido pelo método por Soxhlet com etanol $(25,2 \%)$ e hidroalcóolico (14,0\%). Esse resultado mostra que a temperatura aliada a polaridade intermediária da água foram mais efetivas no processo de extração, o que pode ser explicado devido ao possível rompimento de membranas celulares do vegetal de forma mais facilitada pelo calor, levando a maior interação com os constituintes das folhas de $M$. oleifera na decocção.

Os rendimentos de extrações no presente estudo apresentaram comportamentos similares à de trabalhos anteriores de extratos com matérias-primas vegetais. Em estudo de extração das partes aéreas de tomilho ( $T$. vulgaris), o rendimento também foi maior para extratos obtidos por decocção (11,0\%) do que hidroalcóolico (7,0\%) (MARTINS et al., 2015). Para extratos de folhas de $M$. oleifera os rendimentos para extratos obtidos por decocção em água $(59,2 \%)$ foram superiores a extração convencional utilizando equipamento Soxhlet com etanol 70\% (35,9\%) (VONGSAK et al., 2013), confirmando a influência de escolha do solvente, devido a polaridade intermediaria da água. 
Tabela 1. Rendimento de extrato seco de folhas de $M$. oleifera em porcentagem

\begin{tabular}{|l|c|c|}
\hline Extração & Condições de extração & Rendimento em porcentagem $(\mathrm{m} / \mathrm{m})$ \\
\hline 1 & Soxhlet (solvente etanol) & 25,2 \\
2 & Decocção (solvente água) & 44,0 \\
3 & Extração hidroalcóolica & 14,0 \\
\hline
\end{tabular}

Fonte: Própria (2020).

A Tabela 2 apresenta os resultados de compostos fenólicos totais, capacidade de sequestro do radical DPPH e redução de íon férrico (FRAP) nos extratos de folhas de $M$. oleifera.

Tabela 2. Compostos fenólicos totais e capacidade de sequestro do radial DPPH e de redução do íon férrico (FRAP) dos extratos de folhas de M. oleifera

\begin{tabular}{|l|c|c|c|c|}
\hline Extração & $\begin{array}{c}\text { Condições de } \\
\text { extração }\end{array}$ & $\begin{array}{c}\text { Compostos } \\
\text { fenólicos totais } \\
\left.(\mathrm{mg} \mathrm{ÁG} \mathrm{g})^{-1}\right)\end{array}$ & $\begin{array}{c}\text { Capacidade de } \\
\text { sequestro do } \\
\text { radical DPPH } \\
\left(\mathrm{mg} \mathrm{Trolox} \mathrm{g}^{-1}\right)\end{array}$ & $\begin{array}{c}\text { Capacidade de } \\
\text { redução do íon } \\
\text { férrico } \\
\left(\mathrm{mg} \mathrm{Trolox} \mathrm{g}^{-1}\right)\end{array}$ \\
\hline 1 & $\begin{array}{c}\text { Soxhlet } \\
\text { (solvente etanol) } \\
\text { Decocção } \\
\text { (solvente água) } \\
\text { Extração } \\
\text { hidroalcóolica }\end{array}$ & $36,6 \pm 2,8^{\mathrm{b}}$ & $29,9 \pm 4,2^{\mathrm{a}}$ & $67,7 \pm 1,05^{\mathrm{a}}$ \\
\hline
\end{tabular}

Resultado expresso como média \pm desvio padrão. ${ }^{\text {a-b }}$ Letras iguais na mesma linha não diferem estatisticamente entre si pelo Teste de Tukey $(\mathrm{p}<0,05)$.

Fonte: Própria (2020).

Para quantificação de compostos fenólicos totais, os extratos que apresentaram melhores resultados foram obtidos por extração hidroalcóolica (36,5 $\mathrm{mg}$ ÁG $\left.\mathrm{g}^{-1}\right)$ e decocção em água (35,5 mg ÁG $\left.\mathrm{g}^{-1}\right)$, com valores próximos e sem diferença estatísticas entre si $(\mathrm{p}<0,05)$. $\mathrm{O}$ método de decocção com água apresentou a maior porcentagem de rendimento em massa. Estes dois métodos de extração ainda, apresentaram valores superiores a quantificação obtida por extração convencional utilizando equipamento Soxhlet com etanol (26,6 mg ÁG g $\left.{ }^{-1}\right)$. Esse resultado mostra que os fenóis presentes em folha de $M$. oleifera são preferencialmente extraídos com solvente mais polares devido a maior afinidade, como no uso da extração com apenas água ou mistura de água+etanol. O uso de água e/ou etanol na extração de compostos fenólicos, é responsável por extrair antocianinas, taninos, polifenóis, flavonoides, terpenos e alcaloides com maior facilidade (AZMIR et al., 2013), confirmando assim a influência da polaridade na recuperação dos compostos bioativos presentes em matérias primas vegetais. 
Trabalho anterior de extratos de folhas de M. oleifera de Rodríguez et al. (2015), relataram a variação da quantificação de compostos fenólicos totais de acordo com o tipo de solvente escolhido, os resultados apresentaram que os extratos obtidos por maceração e extração assistida por ultrassom utilizando como solvente uma mistura de água+etanol (50\%), obtiveram melhores resultados (27 a $47 \mathrm{mg}$ ÁG g folha ${ }^{-1}$ ) quando comparados com extratos que utilizaram apenas o solvente orgânico etanol 99\% (3,8 a 8,6 mg ÁG g folha $\left.{ }^{-1}\right)$. Em outra pesquisa de extração de folhas de moringa (PRABAKARAN et al., 2018), os resultados variaram de 89 a $200 \mathrm{mg} \mathrm{ÁG} \mathrm{g}^{-1}$ para extratos obtidos com o uso de metanol, etanol, acetato de etila, água e acetona, sendo o extrato gerado a partir do uso de acetato de etila, responsável pela maior quantificação de compostos fenólicos totais. Este resultado confirma o fator polaridade do solvente durante a extração na recuperação dos compostos fenólicos, uma vez que a metodologia de extração foi a mesma ocorrendo variação apenas entre os cinco solventes utilizados de polaridades distintas.

Mecanismos distintos são utilizados para definir potencial antioxidante. O método de eliminação foi utilizado pela capacidade de sequestro do radical orgânico DPPH e os resultados foram apresentados na Tabela 2. O extrato de folhas de M. oleifera com maior capacidade de eliminação do radical, foi obtido pela condição de extração por decocção em água $(64,9$ mg Trolox g-1), sendo essa também responsável pelo maior rendimento (44\%).

O extrato obtido por extração hidroalcóolica (41,3 $\mathrm{mg}$ Trolox $\left.\mathrm{g}^{-1}\right)$ também apresentou resultado superior ao extrato obtido em extrator Soxhlet com etanol (29,9 mg Trolox $\left.\mathrm{g}^{-1}\right)$, havendo ainda diferença estatística $(\mathrm{p}<0,05)$ entre os extratos. Esse resultado pode ser justificado devido o método de extração utilizando equipamento Soxhlet com etanol, ocorrer durante um período maior e em alta temperatura, levando assim a uma possível degradação dos compostos termolábeis.

Pesquisa recente de extratos de folhas de $M$ oleifera obtidos por extração assistida por homogeneizador, com o uso de três solventes diferentes sendo metanol (100\%), metanol+água (50/50 v) e acetato de etila (100\%) (ROCCHETTI et al., 2020), resultaram em valores próximos aos encontrados no presente estudo, a capacidade de eliminação do radical DPPH variou de 23,54 a 49,55 mg Trolox $\mathrm{g}^{-1}$, sendo o maior resultado apresentado pelo extrato obtido com mistura de água+metanol. Estudos anteriores de extratos de folhas de M. oleifera também apresentaram resultados consideráveis pelo método de sequestro do radical DPPH (FAROOQ et al., 2020; PRABAKARAN et al., 2018; STOHS et al., 2015).

O poder de redução do metal também foi utilizado para definir o potencial antioxidante, sendo realizado o método de redução do íon férrico (FRAP). Como mostra a Tabela 2, os 
extratos obtidos por extração hidroalcóolica (138,5 mg Trolox $\left.\mathrm{g}^{-1}\right)$ e decocção em água (109,4 mg Trolox $\mathrm{g}^{-1}$ ), apresentaram maior poder de redução quando comparados com o método de extração tradicional em extrator Soxhlet com etanol (67,7 mg Trolox $\left.\mathrm{g}^{-1}\right)$. Essas variações podem ser justificadas devido a composição de cada extrato, uma vez que cada solvente é capaz de extrair classes diferentes de compostos, os quais apresentam comportamentos diferentes (GARCIA et al., 2010; RODRÍGUEZ et al., 2015; SAUCEDO et al., 2018). O mesmo comportamento foi verificado por (VONGSAK et al., 2013) em estudo de extratos de folhas de M. oleifera obtidos com o uso de água, etanol $70 \%$ e etanol $50 \%$ como solvente, sendo a maior resposta para redução do íon férrico correspondente ao extrato obtido por maceração com etanol 70\%. Em outro estudo com extratos de folhas de M. oleifera, (ROCCHETTI et al., 2020) obtiveram respostas de redução do íon férrico variando de 13,77 a 58,26 mg Trolox g${ }^{-1}$, sendo esses valores inferiores aos obtidos no presente trabalho.

Compostos fenólicos totais, sequestro do radical DPPH e a redução de íons férrico, estão correlacionados com a capacidade oxidante presente nos extratos de folhas de M. oleifera. A Figura 2 mostra os efeitos das condições de extração causadas na quantificação de compostos fenólicos totais e potencial antioxidante.

Figura 2. Compostos fenólicos totais (CFT), sequestro do radical DPPH e redução de íon férrico (FRAP) obtidos em extratos de folhas de M. oleifera por extração em Soxhlet com etanol (1), decocção com água (2) e extração hidroalcóolica (3). Números de extrações correspondem as condições descritas na Tabela 2.

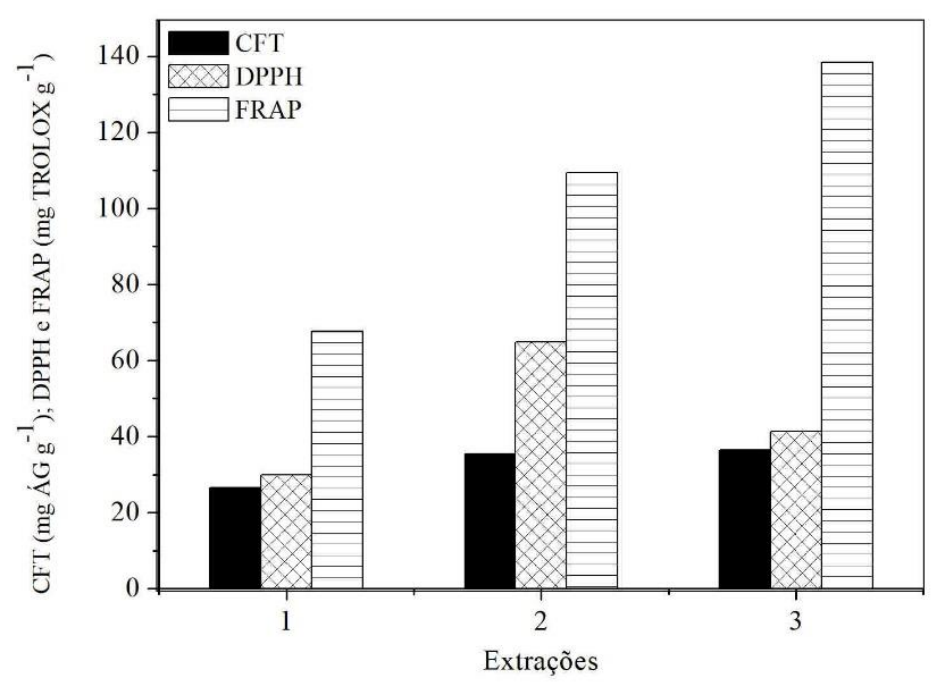

Fonte: Própria (2020).

A influência da forma como o extrato é obtido resulta diretamente na composição individual de cada amostra. Como mostra a Figura 1, é possível verificar os extratos obtidos por decocção em água e extração hidroalcóolica, por apresentarem maior concentração de 
compostos fenólicos totais (CFT), também são responsáveis pela maior capacidade de sequestro do radical DPPH e da redução de íon férrico (FRAP). Essa relação indica que o potencial antioxidante presente nos extratos se deve a elevada concentração de fenóis, que foi mais bem recuperada nos extratos obtidos com o uso de água e mistura de água+etanol como solventes. Extratos de bardana (Arctium lappa) obtidos por extração supercrítica com o uso de $\mathrm{CO}_{2}$ e por Soxhlet com etanol também tiveram essa correlação em que os extratos com maior concentração de compostos fenólicos totais, tiveram maior atividade antioxidante (DE SOUZA et al., 2018).

Com relação avaliação da atividade antimicrobiana, os três extratos de folhas de $M$. oleifera foram testados a fim de verificar a inibição do crescimento bacteriano, para as bactérias Gram positivas e Gram negativas, e os resultados estão detalhados na Tabela 3.

Tabela 3. Avaliação da atividade antimicrobiana de extratos de folha de $M$. oleifera obtidos por diferentes métodos de extração.

\begin{tabular}{|l|c|c|c|}
\hline Bactérias testadas & $\begin{array}{c}\text { Extração em } \\
\text { Soxhlet } \\
\text { (solvente etanol) }\end{array}$ & $\begin{array}{c}\text { Extração por } \\
\text { decocção (solvente } \\
\text { água) }\end{array}$ & $\begin{array}{c}\text { Extração } \\
\text { hidroalcóolica }\end{array}$ \\
\hline
\end{tabular}

Salmonella typhimurium

Escherichia coli

Pseudomonas aeruginosa

Não apresentou Não apresentou inibição

inibição

Não apresentou inibição

Staphylococcus aureus

Listeria monocytogenes

Fonte: Própria (2020).

Como mostra os resultados da Tabela 3, os três extratos não apresentaram zona de inibição para as bactérias testadas na metodologia empregada. Este fato é justificado não apenas pela diferença entre os métodos e solventes utilizados durante a extração para obtenção dos extratos, como também, devido a metodologia empregada de difusão em ágar para as bactérias investigadas. O modo de ação típico esperado dos compostos bioativos, é que ocorra a alteração de permeabilidade e integridade das células bacterianas, por se tratar da complexidade da parede celular, alguns grupos possui uma membrana externa, resultando na característica hidrofílica capaz de limitar a difusão de compostos hidrofóbicos por meio de sua cobertura de lipopolissacarídeos (CZAIKOSKI et al., 2015; DE SOUZA et al., 2018).

Revisões anteriores apresentaram resultados positivos para ação dos extratos de folhas de M. oleifera obtidos por métodos e solventes diferentes, em bactérias Gram positivas e Gram negativas (SAINI et al., 2016; SAUCEDO et al., 2018). Estudo recente de extrato aquoso e extrato etanólico de folhas de M. oleifera (FAROOQ et al, 2020) relataram a capacidade de inibição de ambos os extratos para as bactérias Pseudomonas aeruginosa, Escherichia coli, 
Staphylococcus aureus e Bacillus subtilis. Em outro estudo recente (ROCCHETTI et al., 2020), três extratos de folhas de $M$. oleifera obtidos com uso de solvente metanol (100\%), metanol+água (50/50 v) e acetato de etíla (100\%) apresentaram zona de inibição para as bactérias Gram-positivas Bacillus cereus e Listeria innocua, porém não tiveram inibição para bactérias Gram-negativas Salmonella Enteritidis e Salmonella Typhimurium.

\section{Conclusões}

A partir dos resultados apresentados no presente trabalho, é possível verificar que a metodologia empregada influencia diretamente no rendimento e nas propriedades do extrato, isto porque ocorre variação da polaridade do solvente utilizado, condições de temperatura e tempo de extração empregado, resultando na composição final distinta. Extrato obtido por decocção utilizando apenas água, apresentou melhor rendimento e melhor potencial antioxidante, através da capacidade de sequestro do radical DPPH e de redução do íon férrico. Este tipo de extração está à frente de metodologias convencionais, uma vez que não utiliza solvente orgânico, não gera resíduos, possui baixo tempo de extração, baixo custo e a aplicação do extrato pode ocorrer de forma limpa e segura, sendo o seu uso favorável dentro da indústria de alimentos. Para atividade antimicrobiana, ambos os extratos não inibiram a zona de crescimento das bactérias testadas. Desta forma, é possível considerar extratos de folhas de $M$. oleifera como uma matriz vegetal de interesse maior para estudos futuros e a possíveis aplicações dentro da indústria de alimentos.

\section{Agradecimentos}

Os autores agradecem ao Conselho Nacional de Desenvolvimento Científico e Tecnológico (CNPq) (n404326/2016-1) pelo apoio financeiro concedido e bolsa de iniciação científica .

\section{Referências}

AMAGLO, N. K.; BENNETT, R. N.; LO CURTO, R. B.; ROSA, E. A.S.; LO TURCO, V.; GIUFFRIDA, A.; LO CURTO, A.; CREA, F.; TIMPO, G. M. Profiling selected phytochemicals and nutrients in different tissues of the multipurpose tree Moringa oleifera $\mathrm{L}$., grown in Ghana. Food Chemistry, v. 122, n. 4, p. 1047-1054, 2010.

ANWAR, F.; LATIF, S.; ASHRAF, M.; GILANI, A. H. Moringa oleifera: A food plant with multiple medicinal uses. Phytotherapy Research, v. 21, n. 1, p. 17-25, 2007.

AOAC. Official Methods of Analysis. Association of Official Analytical Chemists International, Arlington, 1999. 
AZMIR, J. et al. Techniques for extraction of bioactive compounds from plant materials: A review. Journal of Food Engineering, v. 117, n. 4, p. 426-436, 2013.

BARRETO, M. B.; FREITAS, J. V. B.; SILVEIRA, E. R.; BEZERRA, A. M. E.; NUNES, E. P.; GRAMOSA, N. V. Constituintes químicos voláteis e não-voláteis de Moringa oleifera Lam., Moringaceae. Revista Brasileira de Farmacognosia, v. 19, n. 4, p. 893-897, 2009.

BOEING, J. S. et al. Evaluation of solvent effect on the extraction of phenolic compounds and antioxidant capacities from the berries: Application of principal component analysis.

Chemistry Central Journal, v. 8, n. 1, p. 1-9, 2014.

CASTRO-LÓPEZ, C. et al. Impact of extraction techniques on antioxidant capacities and phytochemical composition of polyphenol-rich extracts. Food Chemistry, v. 237, p. 1139$1148,2017$.

CELEP, E. et al. Influence of extraction method on enzyme inhibition, phenolic profile and antioxidant capacity of Sideritis trojana Bornm. South African Journal of Botany, v. 121, p. 360-365, 2019.

CZAIKOSKI, K.; MESOMO, M. C.; KRÜGER, R. L.; QUEIROGA, C. L.; CORAZZA, M. L. Extraction of Campomanesia xanthocarpa fruit using supercritical $\mathrm{CO} 2$ and bioactivity assessments. Journal of Supercritical Fluids, v. 98, p. 79-85, 2015.

DE OLIVEIRA FERNANDES, T. et al. Campomanesia adamantium (Myrtaceae) fruits protect HEPG2 cells against carbon tetrachloride-induced toxicity. Toxicology Reports, v. 2, p. 184-193, 2015.

DE SOUZA, A. R. C. et al. Extraction of Arctium Lappa leaves using supercritical $\mathrm{CO} 2$ + ethanol: Kinetics, chemical composition, and bioactivity assessments. Journal of Supercritical Fluids, v. 140, p. 137-146, 2018.

FAROOQ, B.; KOUL, B. Comparative analysis of the antioxidant, antibacterial and plant growth promoting potential of five Indian varieties of Moringa oleifera L. South African Journal of Botany, v. 129, p. 47-55, 2020.

GARCIA-SALAS, P. MORALES-SOTO, A.; SEGURA-CARRETERO, A.; FERNÁNDEZGUTIÉRREZ, A.; Phenolic compound extraction systems for fruit and vegetable samples. Molecules, v. 15, n. 12, p. 8813-8826, 2010.

HAMANY DJANDE, C. Y.; PIATER, L. A.; STEENKAMP, P. A.; MADALA, N. E.; DUBERY, I. A. Differential extraction of phytochemicals from the multipurpose tree, Moringa oleifera, using green extraction solvents. South African Journal of Botany, v. 115, p. 81-89, 2018.

HERRERO, M.; IBÁÑEZ, E. Green processes and sustainability: An overview on the extraction of high added-value products from seaweeds and microalgae. Journal of Supercritical Fluids, v. 96, p. 211-216, 2015.

KALOGO, Y.; ROSILLON, F.; HAMMES, F.; VERSTRAETE, W. Effect of a water extract 
of Moringa oleifera seeds on the hydrolytic microbial species diversity of a UASB reactor treating domestic wastewater. Letters in Applied Microbiology, v. 31, n. 3, p. 259-264, 2000 .

MARTINS, N.; BARROS, L.; SANTOS-BUELGA, C.; SILVA, S.; HENRIQUES, M.; FERREIRA, I. C.F.R. Decoction, infusion and hydroalcoholic extract of cultivated thyme: Antioxidant and antibacterial activities, and phenolic characterisation. Food Chemistry, v. 167, p. 131-137, 2015.

MINUSSI, R. C.; ROSSI, M.; BOLOGNA, L.; CORDI, L.; ROTILIO, D.; PASTORE, G. M; DURÁN, N. Phenolic compounds and total antioxidant potential of commercial wines. Food Chemistry, v. 82, n. 3, p. 409-416, 2003.

MORTON, J. F. The horseradish tree, Moringa pterygosperma (Moringaceae) -A boon to arid lands? The New York Botanical Garden, v. 45, n. 1929, p. 318-333, 1991.

MOYO, B. et al. Nutritional characterization of Moringa (Moringa oleifera Lam.) leaves. African Journal of Biotechnology, v. 10, n. 60, p. 12925-12933, 2011.

NOUMAN, W.; ANWAR, F.; GULL, T.; NEWTON, A.; ROSA, E.; DOMÍNGUEZPERLES, R. Profiling of polyphenolics, nutrients and antioxidant potential of germplasm's leaves from seven cultivars of Moringa oleifera Lam. Industrial Crops and Products, v. 83, p. 166-176, 2016.

OUÉDRAOGO, J. C. W. et al. Enhanced extraction of flavonoids from Odontonema strictum leaves with antioxidant activity using supercritical carbon dioxide fluid combined with ethanol. Journal of Supercritical Fluids, v. 131, p. 66-71, 2018.

OYEYINKA, A. T.; OYEYINKA, S. A. Moringa oleifera as a food fortificant: Recent trends and prospects. Journal of the Saudi Society of Agricultural Sciences, v. 17, n. 2, p. 127136, 2016.

ÖZCAN, M. M. Moringa spp: Composition and bioactive properties. South African Journal of Botany, v. 19, p.25-31, 2020.

PRABAKARAN, M. et al. Polyphenol composition and antimicrobial activity of various solvent extracts from different plant parts of Moringa oleifera. Food Bioscience, v. 26, p. 2329, 2018.

RASHID, U.; ANWAR, F.; MOSER, B.R.; KNOTHE, G.; Moringa oleifera oil: A possible source of biodiesel. Bioresource Technology, v. 99, n. 17, p. 8175-8179, 2008.

ROCCHETTI, G. et al. Phenolic profiling and in vitro bioactivity of Moringa oleifera leaves as affected by different extraction solvents. Food Research International, v. 127, p. 108712, 2020.

RODRÍGUEZ-PÉREZ, C.; QUIRANTES-PINÉ, R.; FERNÁNDEZ-GUTIÉRREZ, A.; SEGURA-CARRETERO, A. Optimization of extraction method to obtain a phenolic compounds-rich extract from Moringa oleifera Lam leaves. Industrial Crops and Products, v. 66, p. 246-254, 2015. 
RODRÍGUEZ-PÉREZ, C.; MENDIOLA, J.A.; QUIRANTES-PINÉ, R.; IBÁÑEZ, E.; SEGURA-CARRETERO, A. Green downstream processing using supercritical carbon dioxide, CO2-expanded ethanol and pressurized hot water extractions for recovering bioactive compounds from Moringa oleifera leaves. The Journal of Supercritical Fluids, v. 116, p. 90-100, 2016.

RUFINO, M. DO S. M.; ALVES, R. E.; BRITO, E. S.; MORAIS, S. M.; SAMPAIO, C. G.; PEREZ-JIMÉNEZ, J. Metodologia Científica: Determinação da Atividade Antioxidante Total em Frutas pelo Método de Redução do Ferro (FRAP). Embrapa, v. 1, p. 1-4, 2006.

RUFINO, M. DO S. M.; ALVES, R. E.; BRITO, E. S.; MORAIS, S. M.; SAMPAIO, C. G.; PEREZ-JIMÉNEZ, J.; Saura-Calixto, F. D. Metodologia Científica: Determinação da atividade antioxidante total em frutas pela captura do radical livre DPPH. Embrapa, p 14, 2007.

SAINI, R. K.; SIVANESAN, I.; KEUM, Y.S. Phytochemicals of Moringa oleifera: a review of their nutritional, therapeutic and industrial significance. 3 Biotech, v. 6, n. 2, p. 203, 2016.

SAUCEDO-POMPA, S.; TORRES-CASTILLO, J. A.; CASTRO-LÓPEZ, C.; ROJAS, R.; SÁNCHEZ-ALEJO, E. J.; NGANGYO-HEYA, M.; MARTÍNEZ-ÁVILA, G. C.G. Moringa plants: Bioactive compounds and promising applications in food products. Food Research International, v. 111, p. 438-450, 2018.

SREELATHA, S.; PADMA, P. R. Antioxidant activity and total phenolic content of Moringa oleifera leaves in two stages of maturity. Plant Foods for Human Nutrition, v. 64, n. 4, p. 303-311, 2009.

STOHS, S. J.; HARTMAN, M. J. Review of the Safety and Efficacy of Moringa oleifera. Phytotherapy Research, v. 29, n. 6, p. 796-804, 2015.

VONGSAK, B. et al. Maximizing total phenolics, total flavonoids contents and antioxidant activity of Moringa oleifera leaf extract by the appropriate extraction method. Industrial Crops and Products, v. 44, p. 566-571, 2013.

ZHAO, S.; ZHANG, D. Supercritical fluid extraction and characterisation of Moringa oleifera leaves oil. Separation and Purification Technology, v. 118, p. 497-502, 2013. 